\title{
Esophageal 99mTc-pertechnetate uptake mimicking an autonomous thyroid adenoma in a patient with subacute thyroiditis: a case report
}

\author{
Ahmad M. Naser, Ayman A. Zayed, Abdullah N. Alhouri, Malik E. Juweid² \\ Department of Internal Medicine, School of Medicine, The University of Jordan/Jordan University Hospital, ${ }^{1}$ Division of Endocrinology and \\ Metabolism, Department of Internal Medicine, School of Medicine, The University of Jordan/Jordan University Hospital, ${ }^{2}$ Department of \\ Radiology and Nuclear Medicine, School of Medicine, The University of Jordan/Jordan University Hospital, Amman, Jordan
}

\begin{tabular}{|c|}
\hline Access this article online \\
\hline Website: www.avicennajmed.com \\
\hline DOI: 10.4103/ajm.ajm_216_19 \\
\hline Quick Response Code: \\
\hline
\end{tabular}

\section{ABSTRACT}

Subacute thyroiditis (SAT) is one of the most common causes of thyrotoxicosis. Thyroid scans with radioiodine or technetium- $99 \mathrm{~m}$ pertechnetate $(99 \mathrm{mTc})$ are often performed in the workup of patients with thyrotoxicosis, particularly to differentiate between SAT and Graves's disease. Although very helpful, thyroid scans are prone to pitfalls that may occasionally lead to misdiagnosis. These pitfalls are largely related to physiologic uptake of radioiodine or $99 \mathrm{mTc}$ in non-thyroidal tissue, such as salivary gland and stomach that may result in false-positive findings. We present herein a very rare case of SAT misdiagnosed as an autonomous thyroid adenoma most likely due to focal $99 \mathrm{mTc}$ uptake in the esophagus. This case may have implications for the management of patients with suspected SAT, who undergo a radioiodine or $99 \mathrm{mT}$ c thyroid scan.

Key words: Autonomous thyroid adenoma, esophageal 99 mTc uptake, hyperthyroidism, subacute thyroiditis, technetium- $99 \mathrm{~m}$ pertechnetate thyroid scan, thyrotoxicosis

\section{INTRODUCTION}

Radioiodine or technetium-99m-pertechnetate (99mTc) thyroid scans are frequently used in the evaluation of thyrotoxicosis. Uptake of radioiodine or $99 \mathrm{mTc}$ by thyrocytes is attributed to the sodium-iodide symporter (NIS). ${ }^{[1]}$ Expression of NIS in several non-thyroidal tissues causes physiological uptake of iodine and $99 \mathrm{mTc}$ in those tissues. ${ }^{[2-4]}$

Painful subacute thyroiditis (SAT) is characterized by thyroid gland inflammation, typically presenting with neck pain, thyroid tenderness, and dysfunction. Radioiodine or $99 \mathrm{mTc}$ scan typically shows markedly decreased tracer uptake.

We present herein a very rare case of SAT misdiagnosed as an autonomous thyroid adenoma most likely due to $99 \mathrm{mTc}$ uptake in the esophagus.

Address for correspondence: Dr. Ayman Aref Zayed, Division of Endocrinology and Metabolism, Department of Internal Medicine, School of Medicine, The University of Jordan/Jordan University Hospital, P.O. Box 13046, Amman 11942, Jordan.

E-mail: baraaayman@gmail.com

\section{CASE PRESENTATION}

A medically free 60 -year-old male patient presented to our endocrinology clinic with pain and swelling in the anterior aspect of his neck of 1-week duration. Three weeks prior to his presentation, he had an upper respiratory tract infection. Clinically the patient was euthyroid.

On examination, his pulse rate was 105 beats per minute and regular and his blood pressure was $145 / 85 \mathrm{~mm} \mathrm{Hg}$. Thyroid examination showed a tender small goiter. He had no retrosternal goiter, bruits, or cervical lymphadenopathy. The rest of the examination was unremarkable. Laboratory

This is an open access journal, and articles are distributed under the terms of the Creative Commons Attribution-NonCommercial-ShareAlike 4.0 License, which allows others to remix, tweak, and build upon the work non-commercially, as long as appropriate credit is given and the new creations are licensed under the identical terms.

For reprints contact: reprints@medknow.com

Cite this article as: Naser AM, Zayed AA, Alhouri AN, Juweid ME. Esophageal $99 \mathrm{mTc}$-pertechnetate uptake mimicking an autonomous thyroid adenoma in a patient with subacute thyroiditis: a case report. Avicenna J Med 2020;10:125-7. 
values showed an elevated serum free $\mathrm{T} 4$ and free $\mathrm{T} 3$ and a suppressed thyroid-stimulating hormone (TSH) [Table 1]. Erythrocyte sedimentation rate (ESR) was $80 \mathrm{~mm}$ in the first hour. His white cell count was $8.54 \times 10^{9} / \mathrm{L}$ with a normal differential. The blood film showed occasional hypersegmented neutrophils.

Initial clinical diagnosis was SAT. To confirm the diagnosis, a 99mTc scan was completed, which showed a focus of intense uptake in the region of the inferior pole of the right thyroid lobe with markedly suppressed uptake of the remainder of the thyroid [Figure 1]. The imaging finding was consistent with a toxic adenoma. Accordingly, the patient was started on carbimazole and propranolol.

Although thyroid ultrasound was ordered on presentation, it was not completed until 8 days later because the patient missed his ultrasound appointment. It revealed multiple small hypoechoic nodules; the largest one in the superior pole of the left lobe measured $5 \mathrm{~mm} \times 10 \mathrm{~mm}$. More importantly, there was no nodule in the inferior pole of the right lobe corresponding to the hot focus seen on his initial thyroid scan. As a result, the diagnosis of toxic thyroid adenoma was questioned. Therefore, carbimazole was discontinued and propranolol was tapered and discontinued.

Repeat Tc scan was performed when the patient's serum TSH normalized [Table 1]. It showed heterogeneous tracer uptake with a warm nodule in the inferior pole of the left thyroid lobe [Figure 2]. The hot focus in the inferior right lobe (which was presumed to be an autonomous adenoma) was no longer seen. A repeat thyroid ultrasound did not reveal significant changes. The final diagnosis was SAT in a patient with multinodular goiter with no scintigraphic evidence of autonomous adenoma.

\section{DISCUSSION}

This case highlights the potential pitfalls associated with interpretation of thyroid Tc scan in patients with thyrotoxicosis.

Our patient presented with thyrotoxicosis and clinical manifestations suggestive of SAT. Typically the thyroid Tc scan during the thyrotoxic phase of SAT is characterized by diffusely decreased uptake, although slightly inhomogeneous tracer distribution is sometimes observed. A focus of increased uptake is unusual and warrants further investigation. ${ }^{[5]}$ The initial thyroid Tc scan of our patient showed a single focus of increased uptake in the region of the inferior pole of the right lobe of the thyroid [Figure 1]. The absence of an ultrasound nodule corresponding to the site of the hot focus indicates that the radioactive focus was extrathyroidal. Potential extrathyroidal sites include the trachea, esophagus, and bone marrow of the vertebrae corresponding to the level of the thyroid gland.

Radiotracer uptake in the bone marrow of the femora and tibiae bones has only been reported in an athletic runner ${ }^{[6]}$ Radiotracer uptake in the vertebral bone marrow has not been reported. Our patient was not involved in heavy running activities and was not known to have a bone marrow disorder. Esophageal uptake has been reported in Zinker's diverticulum, epinephric diverticulum, achalasia, and scarring of the esophagus. ${ }^{[7]}$ However, because the hot focus in our patient's thyroid scan was not seen on the repeat scan it is most likely that the hot focus was due to a temporary cause rather than a fixed one. This makes the aforementioned esophageal and bone marrow disorders unlikely to be the cause of the thyroid activity observed. Tracheal uptake was reported with the use of aerosol drugs ${ }^{[8]}$ Our patient was not

\begin{tabular}{|c|c|c|c|c|c|}
\hline \multirow[t]{2}{*}{ Date } & Free T4 & Free T3 & TSH & ESR & Comment \\
\hline & $\begin{array}{l}9.01-19.05 \\
(\mathrm{pmol} / \mathrm{L})\end{array}$ & $\begin{array}{l}.7 I-3.71 \\
(\mathrm{pmol} / \mathrm{L})\end{array}$ & $\begin{array}{l}0.35-4.94 \\
(\mathrm{mU} / \mathrm{L})\end{array}$ & $\overline{0-25(\mathrm{~mm} / \mathrm{lst} h)}$ & \\
\hline March 3 & 44.08 & 11.14 & 0.009 & 80 & Propranolol was started. \\
\hline March 8 & & & & & $\begin{array}{l}\text { Technetium-99m-pertechnetate thyroid scan was performed. The } \\
\text { patient was diagnosed with toxic thyroid adenoma. Carbimazole } \\
\text { was started. }\end{array}$ \\
\hline March 16 & 22.16 & 7.21 & 0.01 & 29 & $\begin{array}{l}\text { Thyroid ultrasound was performed. Carbimazole was discontinued } \\
\text { and propranolol was tapered. }\end{array}$ \\
\hline April I & 8.78 & 3.23 & 5.28 & 10 & \\
\hline April 29 & 5.86 & 3.19 & 64.34 & 7 & The patient required a short course of thyroxine therapy \\
\hline May 28 & 12.01 & & 4.03 & & $\begin{array}{l}\text { Thyroid ultrasound, scan, and uptake were repeated. } \\
\text { Antithyroglobulin antibodies were tested and came positive. }\end{array}$ \\
\hline August I & 15.20 & & 1.50 & & \\
\hline
\end{tabular}

$\mathrm{TSH}=$ thyroid-stimulating hormone, $\mathrm{ESR}=$ erythrocyte sedimentation rate 


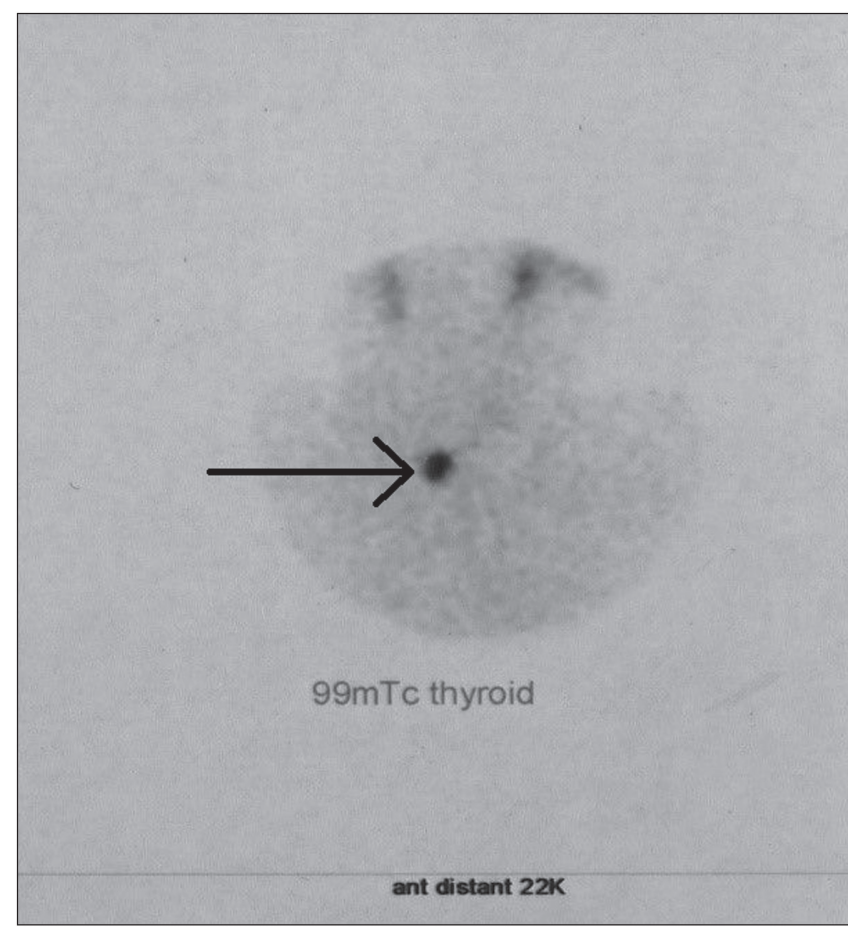

Figure 1: Initial thyroid scan obtained 20 min after $5 \mathrm{mCi}(185 \mathrm{MBq})$ intravenous injection of $99 \mathrm{mTc}$-pertechnetate showing a hot focus (arrow) in the inferior pole region of the right thyroid lobe with markedly decreased uptake of the remainder of the thyroid

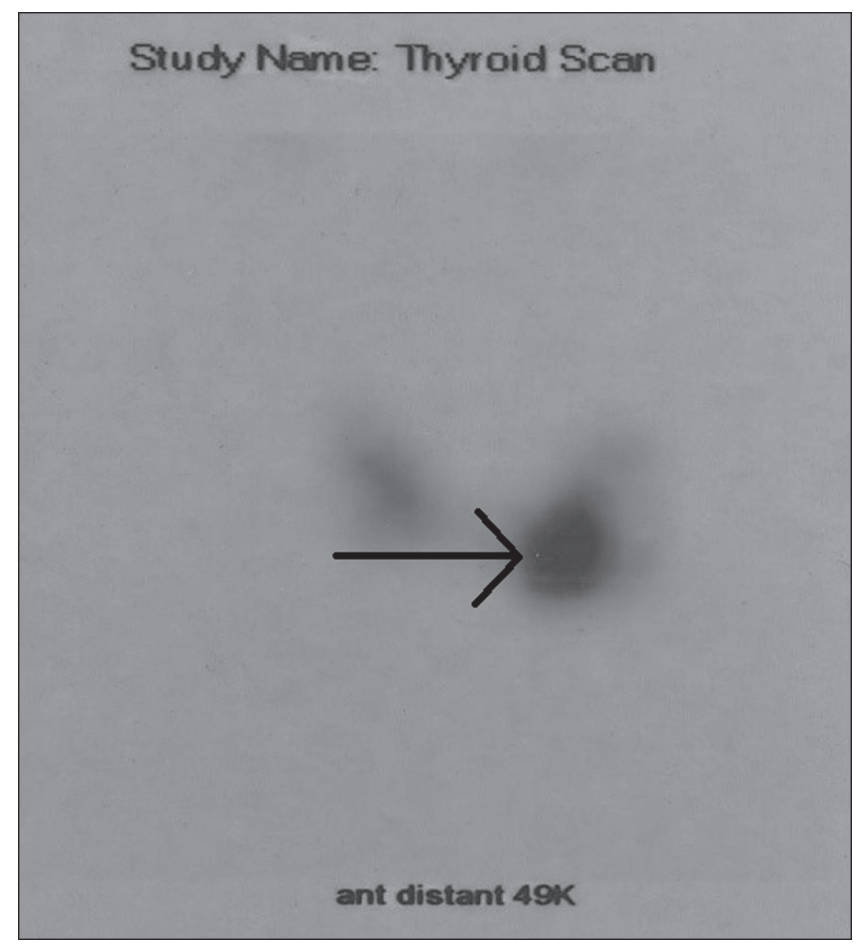

Figure 2: The follow-up 99mTc-pertechnetate scan showing heterogeneous tracer uptake with a warm nodule in the left inferior pole and a cold nodule laterally in the mid left lobe (arrows). There was no evidence of the right inferior pole hot nodule

using any local aerosol, making it unlikely that the observed hot focus was located in the trachea.
Based on the above, transient Tc activity in the esophagus was the most likely explanation for our patient's thyroid scan finding. It is widely known that retention of saliva and/ or refluxed gastric secretions in the esophagus can explain radiotracer uptake in the esophagus. ${ }^{[9]}$ Asking the patient to drink water just prior to the scan can minimize this problem by washing tracer activity in the esophagus. ${ }^{[10]}$ Our conclusion is limited by the fact that thyroid ultrasound was performed 8 days after the thyroid Tc scan. However, we think that this difference in time between the two imaging studies is of no significance. In conclusion, the uniqueness of our case is that it represents an esophageal Tc uptake mimicking an autonomous thyroid adenoma in a patient with SAT. The esophageal uptake was most likely due to retention of saliva and/or refluxed gastric secretions. This highlights the importance of correlating thyroid nuclear scan with ultrasonographic findings and clinical presentation.

\section{Financial support and sponsorship Nil.}

\section{Conflicts of interest}

There are no conflicts of interest.

\section{REFERENCES}

1. Watkinson J. Thyroid cancer: A comprehensive guide to clinical management, 2nd ed. Ann R Coll Surg Engl 2008;90:360.

2. Spitzweg C, Joba W, Eisenmenger W, Heufelder AE. Analysis of human sodium iodide symporter gene expression in extrathyroidal tissues and cloning of its complementary deoxyribonucleic acids from salivary gland, mammary gland, and gastric mucosa. The Journal of Clinical Endocrinology \& Metabolism 1998;83:1746-51.

3. Hiromatsu Y, Ishibashi M, Miyake I, Nonaka K. Technetium-99m tetrofosmin imaging in patients with subacute thyroiditis. Eur J Nucl Med 1998;25:1448-52.

4. Riesco-Eizaguirre G, Santisteban P. A perspective view of sodium iodide symporter research and its clinical implications. Eur J Endocrinol 2006; 155:495-512.

5. Czepczyński R. Nuclear medicine in the diagnosis of benign thyroid diseases. Nucl Med Rev Cent East Eur 2012;15:113-9.

6. Bohnen NI, Charron M. Isolated lower extremity I-131 bone marrow uptake in a runner. Clin Nucl Med 2001;26:163-4.

7. Oh JR, Ahn BC. False-positive uptake on radioiodine whole-body scintigraphy: Physiologic and pathologic variants unrelated to thyroid cancer. Am J Nucl Med Mol Imaging 2012;2:362-85.

8. Kienast O, Hofmann M, Ozer S, Dobrozemsky G, Dudczak R, Kurtaran A. Retention of iodine-131 in respiratory tract in a patient with papillary thyroid carcinoma after radionuclide therapy: A rare false-positive finding. Thyroid 2003;13:509-10.

9. Song H-C, Kim S-M, Heo Y-J, Bom H-S. Retention of iodine-131 in a thoracic esophageal diverticulum mimicking metastatic thyroid cancer. Clin Nucl Med 2002;27:896-7.

10. Dhawan VM, Kaess KR, Spencer RP. False positive thyroid scan due to Zenker's diverticulum. J Nucl Med 1978;19:1231-2. 